\title{
A Mathematical Model of Neutral Lipid Content in terms of Initial Nitrogen Concentration and Validation in Coelastrum sp. HA-1 and Application in Chlorella sorokiniana
}

\author{
Zhenhua Yang, Yue Zhao, Zhiyong Liu, Chenfeng Liu, Zhipeng Hu, and Yuyong Hou \\ Tianjin Key Laboratory for Industrial Biological Systems and Bioprocessing Engineering, Tianjin Institute of Industrial Biotechnology, \\ Chinese Academy of Sciences, Tianjin, China
}

Correspondence should be addressed to Yuyong Hou; hou_yy@tib.cas.cn

Received 12 April 2016; Revised 6 November 2016; Accepted 19 December 2016; Published 18 January 2017

Academic Editor: Ramkrishna Sen

Copyright (C) 2017 Zhenhua Yang et al. This is an open access article distributed under the Creative Commons Attribution License, which permits unrestricted use, distribution, and reproduction in any medium, provided the original work is properly cited.

\begin{abstract}
Microalgae are considered to be a potential major biomass feedstock for biofuel due to their high lipid content. However, no correlation equations as a function of initial nitrogen concentration for lipid accumulation have been developed for simplicity to predict lipid production and optimize the lipid production process. In this study, a lipid accumulation model was developed with simple parameters based on the assumption protein synthesis shift to lipid synthesis by a linear function of nitrogen quota. The model predictions fitted well for the growth, lipid content, and nitrogen consumption of Coelastrum sp. HA-1 under various initial nitrogen concentrations. Then the model was applied successfully in Chlorella sorokiniana to predict the lipid content with different light intensities. The quantitative relationship between initial nitrogen concentrations and the final lipid content with sensitivity analysis of the model were also discussed. Based on the model results, the conversion efficiency from protein synthesis to lipid synthesis is higher and higher in microalgae metabolism process as nitrogen decreases; however, the carbohydrate composition content remains basically unchanged neither in HA-1 nor in C. sorokiniana.
\end{abstract}

\section{Introduction}

Microalgae have been considered as a potential biomass feedstock for renewable energy technologies due to its high cellular concentration of lipids, resources sustainability, and greater potential environmental benefits than conventional biofuel [1-3]. However, realizing industrial production of algal-derived biofuel faces many obstacles; in particular, the cost and technical constraints are the two currently major limits for widespread adoption of algae oil [4-7]. Therefore, algae-derived oil development may require progress in various scientific and engineering disciplines, such as optimizing cultivation parameters to increase lipid productivities $[4,8$, 9]. Considering the assumption that the algae biomass (dry weight) was the sum of protein, lipids, and carbohydrates [5], the lipid productivity could be affected by protein and carbohydrate synthesis. Although the excess carbon fixed by photosynthesis is changed to triacylglycerides synthesis for lipid accumulation under nitrogen starvation, the growth rate of microalgae is reduced since fundamental proteins cannot be synthesized [5, 10-12]. On the other hand, mechanism on neutral lipid synthesis about how TAGs are biosynthesized is still in its early stage. $\mathrm{Li}$ et al. and Hong et al. [13, 14] observed the competitive relationship between TAGs and carbohydrates biosynthesis after nitrogen depletion. Interestingly, some strains show significant higher quantities of both carbohydrates and lipid during nitrogen-deprived condition $[15,16]$. For this reason a suitable way to increase both lipid content and biomass is an urgent and pressing need for producing microalgal biofuels.

The growth model of algae has been well developed with various algae species under different growth environment [17-20]. However, the easily adaptable model of algal lipid content is rarely published with respect to various nitrogen concentrations. A new widely simplified applicable mathematical model should be developed for various nitrogen treatments to fully understand the microalgae lipid productivity.

In this study, the lipid content was represented as a linear function of nitrogen quota which was calculated based on the mass balance in the growth medium to study 
lipid accumulation. It was validated in Coelastrum sp. HA-1 under various initial nitrogen concentrations and applied in Chlorella sorokiniana at different light conditions. The growth was modeled by a nonautonomous differential equation incorporating the logistic equation and adjustment function $[14,15]$, whereas Michaelis-Menten function was used to model the nitrogen uptake $[18,19]$.

\section{Methods}

2.1. Algae Growth Kinetic Modeling. In order to obtain the relationship between culture conditions and the specific growth rate, a simple but useful model (1) was expressed in this work by a nonautonomous differential equation [21-23].

$$
\frac{1}{X(t)} \cdot \frac{d X(t)}{d t}=\mu=\mu_{\max } \cdot \alpha(t) \cdot\left(1-\frac{X(t)}{X_{\max }}\right),
$$

where $\mu$ is the specific growth rate of cell population $\left(\right.$ day $\left.^{-1}\right)$, $X(t)$ is the microalgal concentration at time $t\left(\mathrm{~g} \mathrm{dw} \cdot \mathrm{L}^{-1}\right)$, $\mu_{\max }$ is the maximum specific growth rate of cells $\left(\right.$ day $\left.^{-1}\right)$, $\alpha(t)$ is the adjustment function, and $X_{\max }$ is the maximum microalgal concentration during cultivation $\left(\mathrm{gdw} \cdot \mathrm{L}^{-1}\right)$.

Baranyi and Roberts [21, 22] reported $\alpha(t)$ based on an assumption that the growth of cells in the lag phase was inhibited by intracellular substance. The adaptation of microalgal cells can be described by $\alpha(t)$ when cells entered in a new condition of the bioreactor. Adjustment function is expressed as

$$
\begin{aligned}
& \alpha(t) \\
& =\frac{\exp \left(-h_{0}\right)}{\exp \left(-\mu_{\max } \cdot t\right)+\exp \left(-h_{0}\right)-\exp \left(-\mu_{\max } \cdot t-h_{0}\right)},
\end{aligned}
$$

where $h_{0}$ is called the dimensionless parameter of BaranyiRoberts model. Adjustment function has the following characteristics: it is a monotonic function; $\lim _{t \rightarrow \infty} \alpha(t)=1$; when $h_{0}<0, \alpha(t)>1$; when $h_{0} \geq 0,0 \leq \alpha(t)<1$.

\subsection{Nitrogen Assimilation and Nitrogen Quota Modeling. In} this work, we assumed that nitrogen uptake is a function of external nitrogen concentration; thus, Michaelis-Menten function $[18,19]$ was used to simulate nitrogen uptake during cultivation.

The differential equation for nitrogen uptake is expressed as

$$
\frac{d N(t)}{d t}=-v_{m} \cdot \frac{N(t)}{N(t)+K_{N}} \cdot X(t)
$$

where $N(t)$ is the external nitrogen concentration at time $t\left(\mathrm{~g} \mathrm{~N} \cdot \mathrm{L}^{-1}\right), v_{m}$ is the maximum nitrogen uptake rate ( $\mathrm{g} \mathrm{N} \mathrm{g}^{-1} \mathrm{dw} \cdot \mathrm{day}^{-1}$ ), and $K_{N}$ is the half-saturation coefficient of nitrogen uptake $\left(\mathrm{g} \mathrm{N} \cdot \mathrm{L}^{-1}\right)$.

Integration of (3) yields the remaining nitrogen in the growth media at time $t$. The nitrogen quota that is defined as the rate between the mass of internal nitrogen and total dry weight of biomass can be obtained by mass balance [24]. It is expressed as

$$
Q(t)=\frac{N_{0}-N(t)+X_{0} \cdot Q_{0}}{X(t)},
$$

where $Q(t)$ is the nitrogen quota at time $t$ ( $\left.\mathrm{g} \mathrm{N} \mathrm{g}^{-1} \mathrm{dw}\right), N_{0}$ is the initial nitrogen concentration in growth media $\left(\mathrm{g} \mathrm{N} \cdot \mathrm{L}^{-1}\right)$, $Q_{0}$ is the initial nitrogen quota $\left(\mathrm{g} \mathrm{N} \mathrm{g}^{-1} \mathrm{dw}\right)$, and $X_{0}$ is the initial microalgal concentration $\left(\mathrm{g} \mathrm{dw} \cdot \mathrm{L}^{-1}\right)$.

2.3. Lipid Accumulation Modeling. The conversion efficiency from protein synthesis to lipid or carbohydrate synthesis is higher and higher in microalgae metabolism process when nitrogen is depleted causing a change in the biomass composition [20,25]. Once nitrogen is depleted, lipid content increased from 9 percent to 62 percent of dry weight; however, protein content decreased from 53 percent to 23 percent of dry weight, and carbohydrate content increased a little in the biomass [20]. The lipid accumulation model thus was expressed as (5) by assuming that the biomass is made up of protein, lipid, and carbohydrate, and protein synthesis shifts to lipid synthesis with nitrogen depletion.

$$
L(t)=1-k \cdot Q(t)-c,
$$

where $L(t)$ is the lipid content ( L Lipid $^{-1} \mathrm{dw}$ ), $k$ is the nitrogen-to-protein conversion factor, and $c$ is the carbohydrate content of biomass ( $\mathrm{g}$ carbohydrate $\mathrm{g}^{-1} \mathrm{dw}$ ).

After rearranging (4)-(5) and replacing $X_{0} \cdot Q_{0}$ with $\Phi$, the lipid content becomes

$$
L(t)=1-k \cdot \frac{N_{0}-N(t)+\Phi}{X(t)}-c .
$$

We could easily obtain the lipid content according to (6) by analyzing nitrogen concentrations and microalgal biomass.

2.4. Experimental Approach. The seeds of Coelastrum sp. and C. sorokiniana were cultured to logarithmic phase for further use in $250 \mathrm{~mL}$ Erlenmeyer flasks with $150 \mathrm{~mL} \mathrm{~F}$ medium (nutrient elements are twofold compared to those in $f / 2$ medium) and Kuhl medium under continuous illumination $\left(100 \mu \mathrm{mol} \cdot \mathrm{m}^{-2} \cdot \mathrm{s}^{-1}\right)$, respectively $[26,27]$. The temperature was maintained at $25^{\circ} \mathrm{C}$; pH was adjusted to 7.5 initially.

In order to evaluate the effect of nitrogen on the dry weight and lipid yield of the Coelastrum sp. within 24 days, the $\mathrm{F}$ medium with $150 \mu \mathrm{mol} \cdot \mathrm{m}^{-2} \cdot \mathrm{s}^{-1}$ was modified by adjusting $\mathrm{NaNO}_{3}$ concentrations to $0.075,0.15,0.3,0.6$, and $0.9 \mathrm{~g} \cdot \mathrm{L}^{-1}$. For model application on fresh water microalgae C. sorokiniana, the cells were cultivated in modified Kuhl medium with $1 \mathrm{~g} \cdot \mathrm{L}^{-1} \mathrm{NaNO}_{3}$ under different light intensities (50, 100, and $\left.200 \mu \mathrm{mol} \cdot \mathrm{m}^{-2} \cdot \mathrm{s}^{-1}\right)$. In the experiments, $50 \mathrm{~mL}$ logarithmic phase seed cells were centrifuged and resuspended with the corresponding medium to wipe out the effect of residual nitrogen source and then transferred to glass columns $(4.1 \mathrm{~cm}$ in diameter, $37 \mathrm{~cm}$ in height) with $2 \%(\mathrm{v} / \mathrm{v}) \mathrm{CO}_{2}$ at $25^{\circ} \mathrm{C}$. The cell concentration $\left(\mathrm{OD}_{680}\right)$ of each column reactor was 


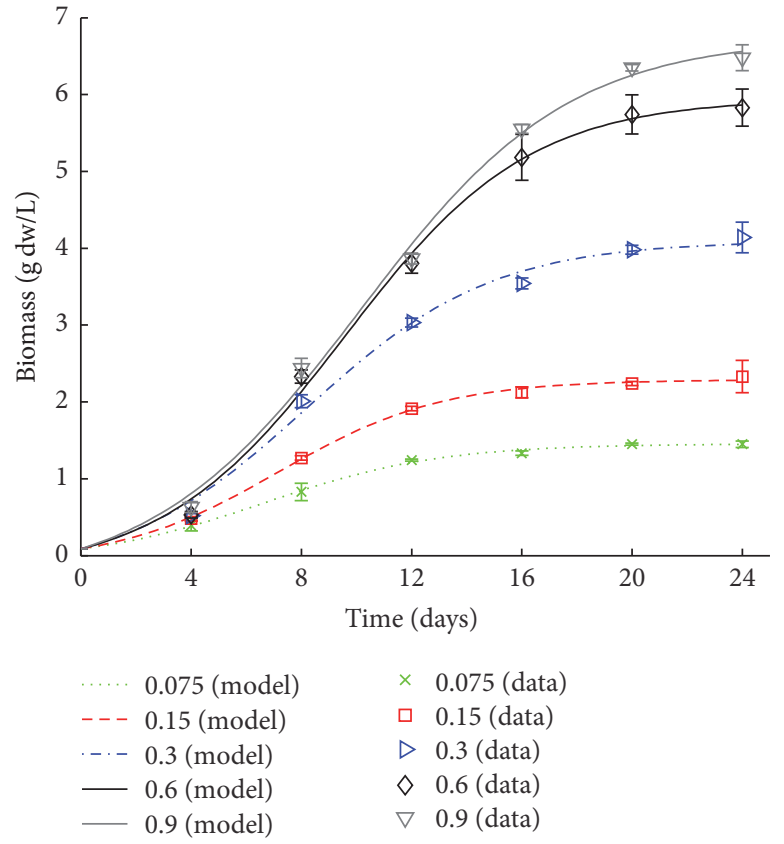

(a)

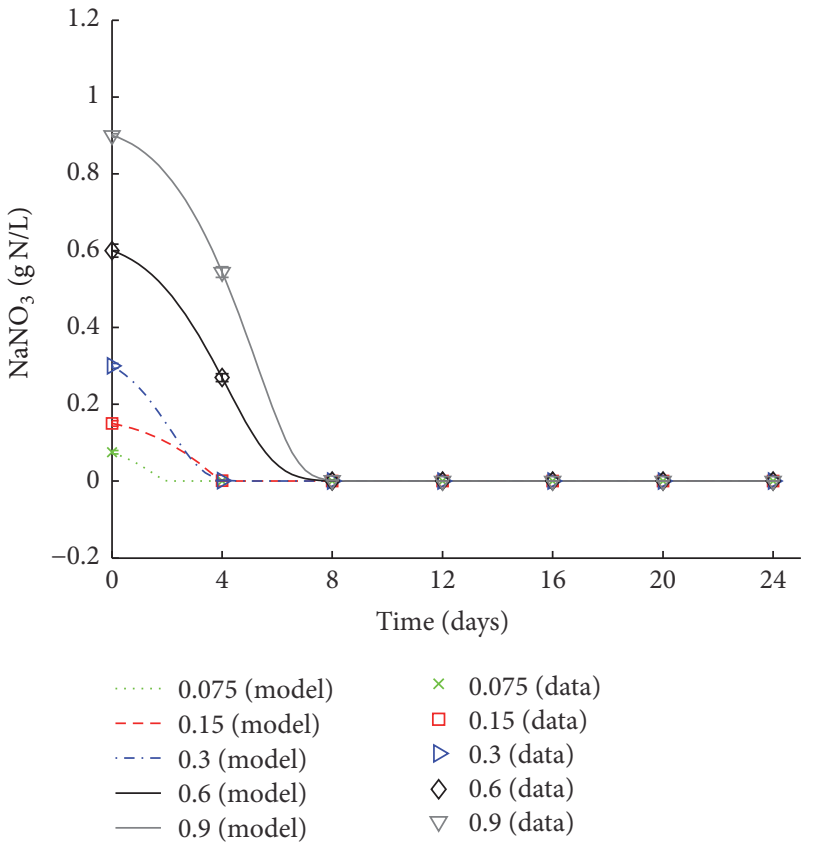

(b)

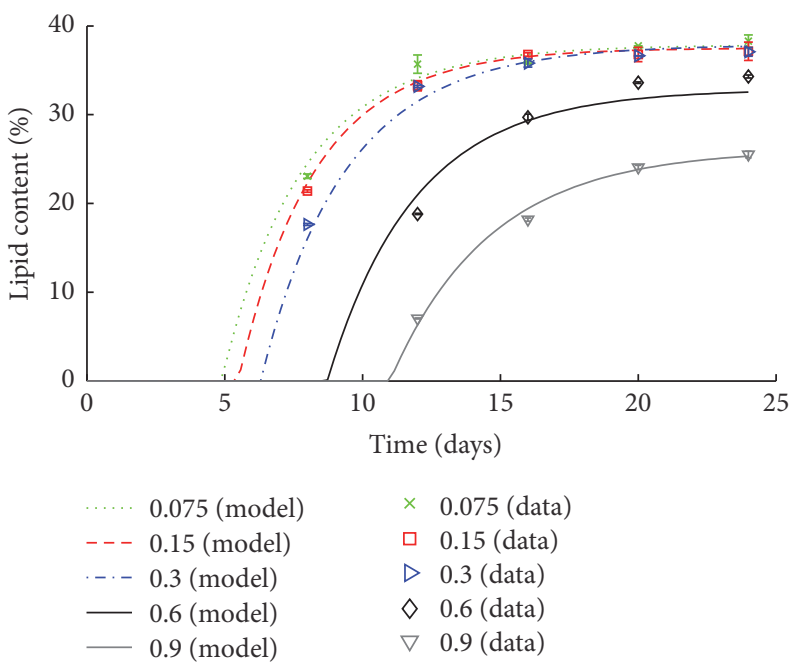

(c)

FiguRE 1: Simulation results versus experimental data for dry weight (a), nitrogen consumption (b), and lipid content (c) of Coelastrum sp. HA-1 at different initial $\mathrm{NaNO}_{3}$ concentrations.

approximately 0.2 . For dry weight measurement, microalgal culture sample $(10 \mathrm{~mL})$ was filtered through pretreated glassfiber filter paper $(0.8 \mu \mathrm{m}$ pore size); then 0.5 mole solution of ammonium formate was used to wash the filter paper in order to remove salt. Finally, the filter paper was dried $24 \mathrm{~h}$ at $105^{\circ} \mathrm{C}[28,29]$. The dry weight was calculated by the difference between the cell-containing dried filter paper and the weight before filtration. The lipid content and nitrogen concentration were measured according to Yuan et al.s method [29]. All experiments were performed with triplicates.

2.5. Parameter Estimation. In order to determine the parameter values of (6), the MATLABlsqcurvefit routine was firstly used to estimate the parameter values of (1) and (3) which were integrated by Runge-Kutta integration method. Then, (6) was used for fitting the experimental data of lipid content under different initial nitrogen concentrations. For HA-1, the parameter values and simulation $R^{2}$ were shown at different initial nitrogen concentrations in Table 1 . The parameter values of the model for predicting growth, lipid content, and nitrogen uptake of Chlorella sorokiniana were in Table 2.

\section{Results and Discussion}

3.1. Effect of Initial Nitrogen Concentration on the Final Lipid Content in Coelastrum sp. HA-1. The final lipid content of HA-1 under low initial nitrogen concentration was higher than those with high nitrogen concentration (Figure 1(c)). 


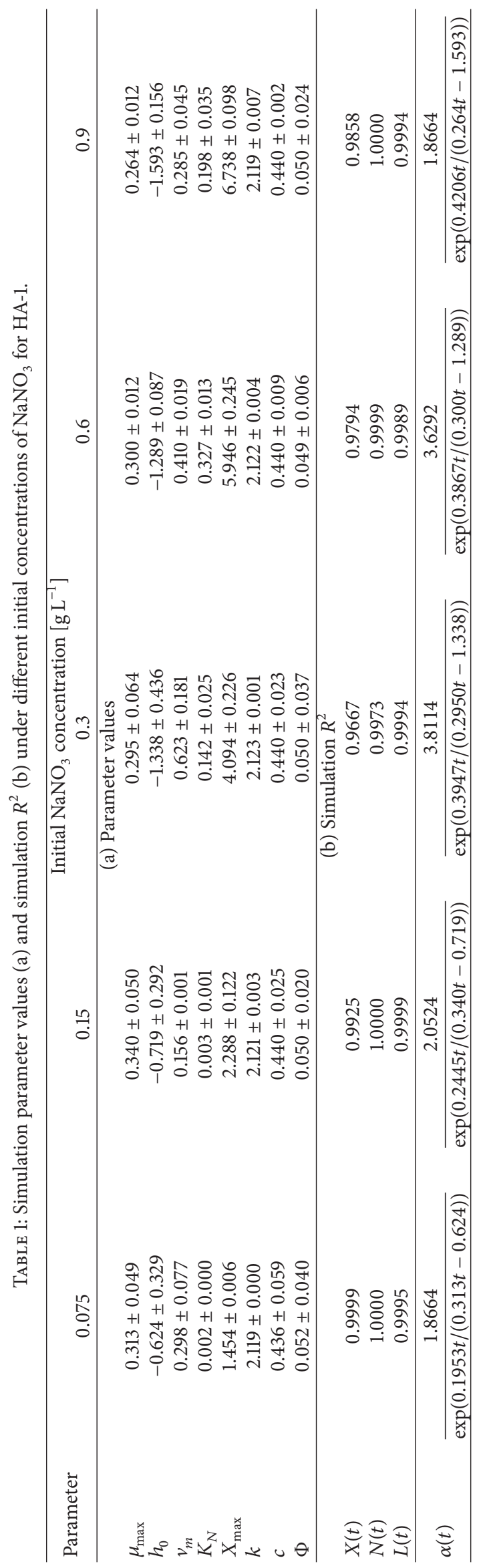




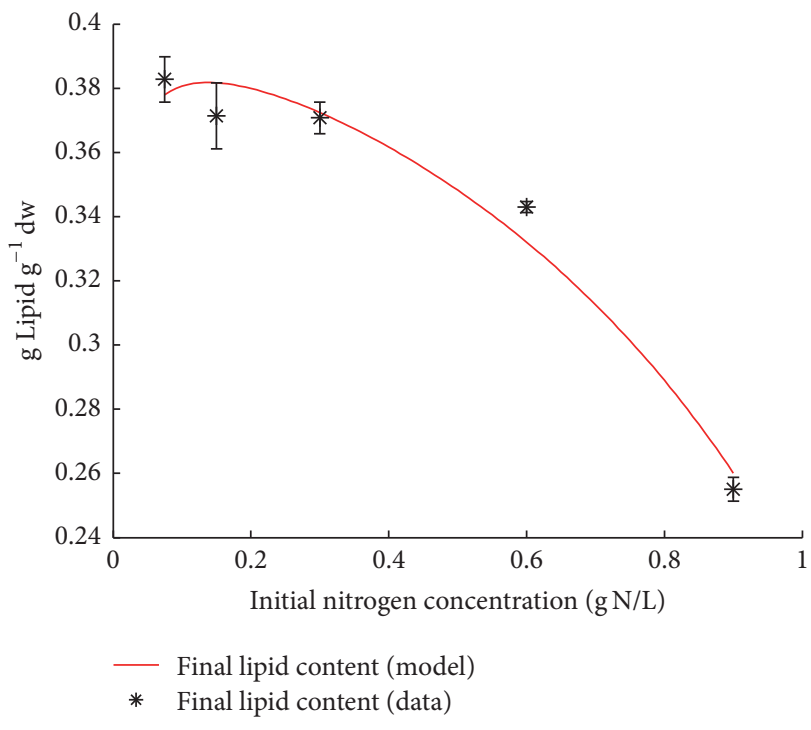

(a)

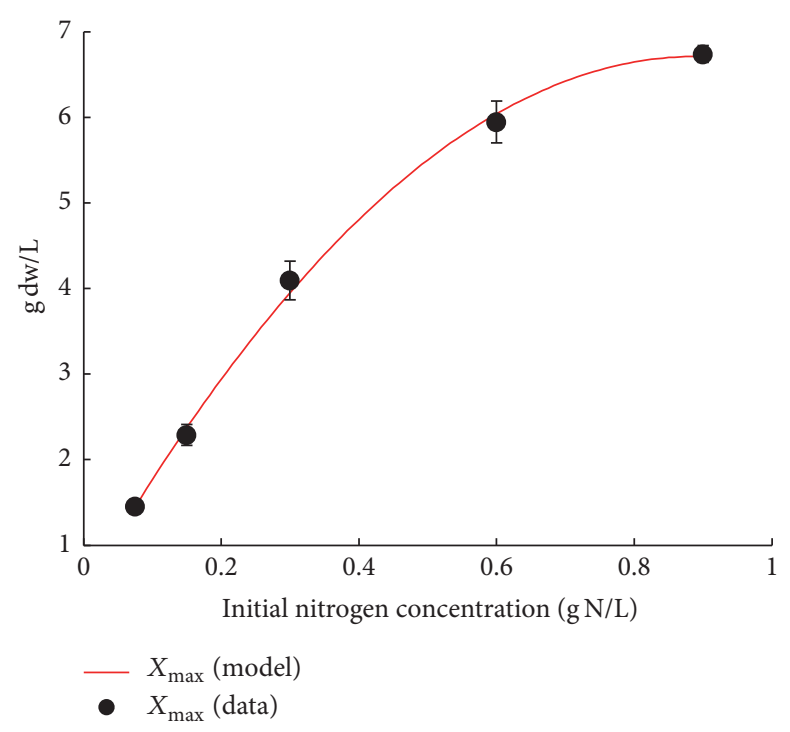

(b)

FIGURE 2: Simulation results versus parameter values for the final lipid content of Coelastrum sp. HA-1 (a) and the maximum algal concentration (b) under different initial $\mathrm{NaNO}_{3}$ concentrations.

TABLE 2: Simulation parameter values at different light intensities for C. sorokiniana.

\begin{tabular}{lccc}
\hline Parameter & \multicolumn{3}{c}{ Light intensity $\left[\mu \mathrm{mol} \cdot \mathrm{m}^{-2} \cdot \mathrm{s}^{-1}\right]$} \\
& 50 & 100 & 200 \\
\hline$\mu_{\max }$ & 0.466 & 0.297 & 0.455 \\
$h_{0}$ & -1.493 & -1.910 & -1.559 \\
$v_{m}$ & 0.285 & 0.285 & 0.285 \\
$K_{N}$ & 0.198 & 0.198 & 0.198 \\
$X_{\max }$ & 1.009 & 1.228 & 0.678 \\
$k$ & 0.735 & 0.775 & 0.746 \\
$c$ & 0.113 & 0.093 & 0.102 \\
$\Phi$ & $5.794 E-07$ & $3.450 E-03$ & $2.670 E-04$ \\
\hline
\end{tabular}

It might be explained from the point of energy balance that cell growth will not continue under low nitrogen concentration. However, carbon fixation is still in progress at rates exceeding the needs of the cell. In order to maintain a safe turnover of the ATP and reductant pools sustained by light reaction, neutral lipid synthesis is upregulated because fatty acid production needs more ATP and reductant than other substance production in cell; neutral lipids store significantly more energy and its synthesis requires twice energy than carbohydrate or protein [30].

In order to quantify the relationship between initial nitrogen concentration and the final lipid content in HA-1, a correlation equation of $X_{\max }$ was firstly given by polynomial fitting with initial nitrogen concentrations. The empirical correlation equation of $X_{\max }$ was

$$
X_{\max }=-7.891 \cdot N_{0}^{2}+14.070 \cdot N_{0}+0.439 .
$$

Based on (6), the final lipid content could be calculated by initial nitrogen concentration when algal concentration reached the maximum value. After rearranging (6) and (7), the final lipid content could be expressed as

$$
L_{f}=0.56-\frac{2.120 \cdot\left(N_{0}+0.0495\right)}{-7.891 \cdot N_{0}^{2}+14.070 \cdot N_{0}+0.439},
$$

where $L_{f}$ is the final lipid content $\left(\mathrm{gLipid}^{-1} \mathrm{dw}\right)$. The simulation result of (8) is meaning for final lipid content data (Figure 2(a)).

The simulation of (7) agreed with the initial nitrogen concentration data to a great degree (Figure 2(b)), and the simulation $R^{2}$ was 0.9982 . Equation (7) showed that the relationship between $X_{\max }$ and initial concentration of nitrogen was not linear, especially when the initial concentration of nitrogen was higher in growth medium (Figure 2(b)). Compared to high nitrogen conditions, the maximum microalgal concentration increased significantly with the nitrogen concentration increasing under low nitrogen conditions. The biomass with $0.3 \mathrm{~g} \cdot \mathrm{L}^{-1}$ nitrogen was about 1.86 -fold compared to those in $0.075 \mathrm{~g} \cdot \mathrm{L}^{-1}$ nitrogen medium. While the nitrogen increased from 0.6 to $0.9 \mathrm{~g} \cdot \mathrm{L}^{-1}$, the maximum microalgal concentration was only increased about $11.1 \%$. Although the growth decreased with nitrogen concentration increasing, the final microalgal concentration increased to $6.48 \mathrm{~g} \cdot \mathrm{L}^{-1}$. The results strongly imply that growth is limited by another nutrient or light intensity when BG-11 is rich in nitrogen. A similar result was also reported by Packer et al. [24].

Equation (8) showed that the final lipid content could be described as a function of initial nitrogen concentration. Decreasing the initial nitrogen concentration is a good method to obtain high lipid production especially for outdoor cultivation. It is important to note that the range of initial concentration of nitrogen for artificial regulation needs to be obtained based on experimental data under a certain 


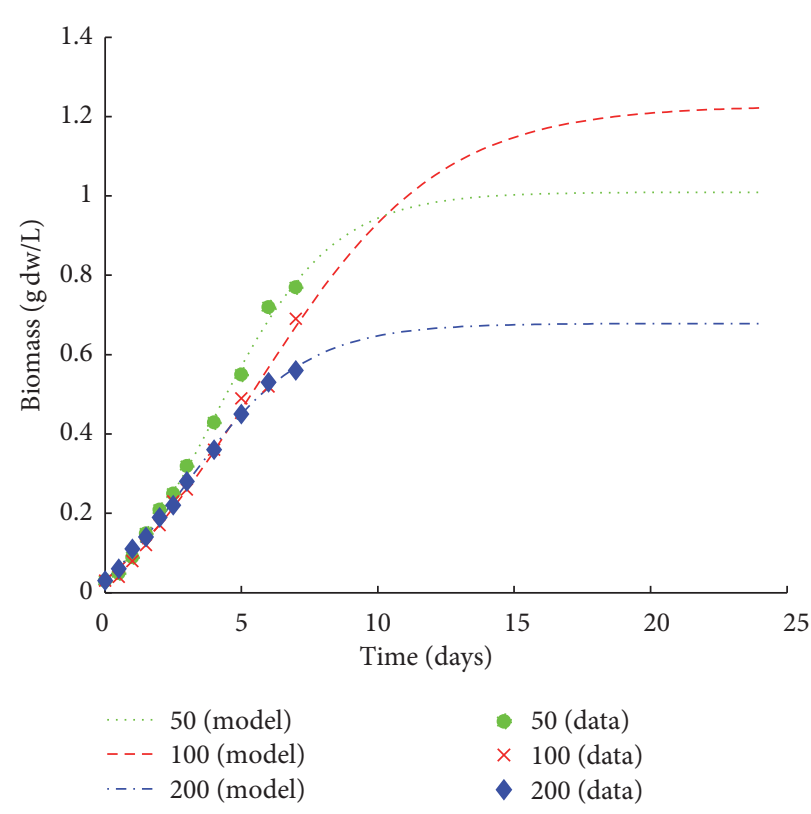

(a)
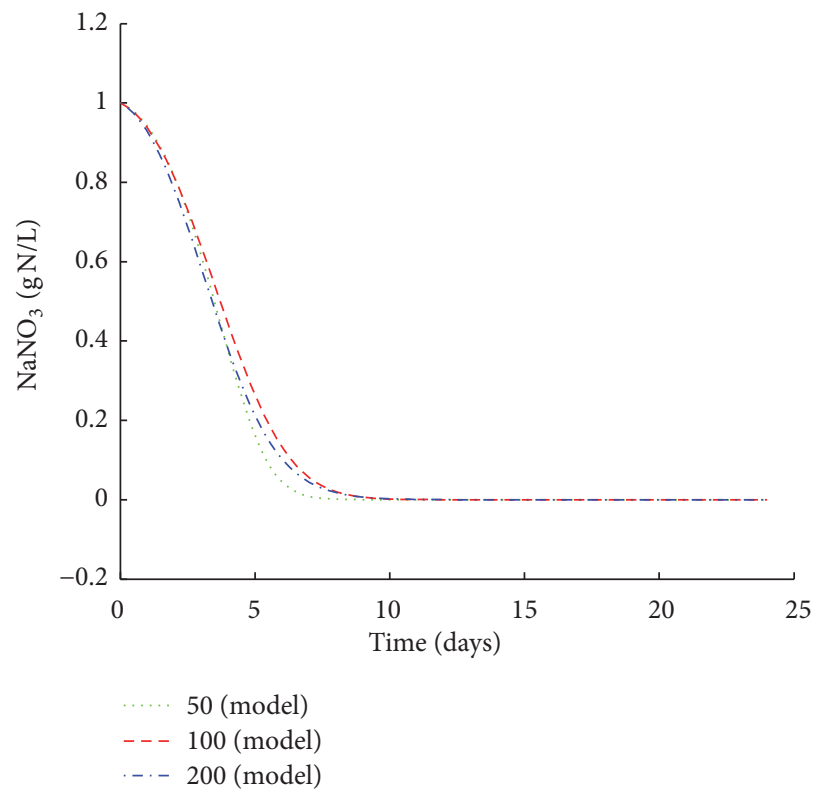

(b)

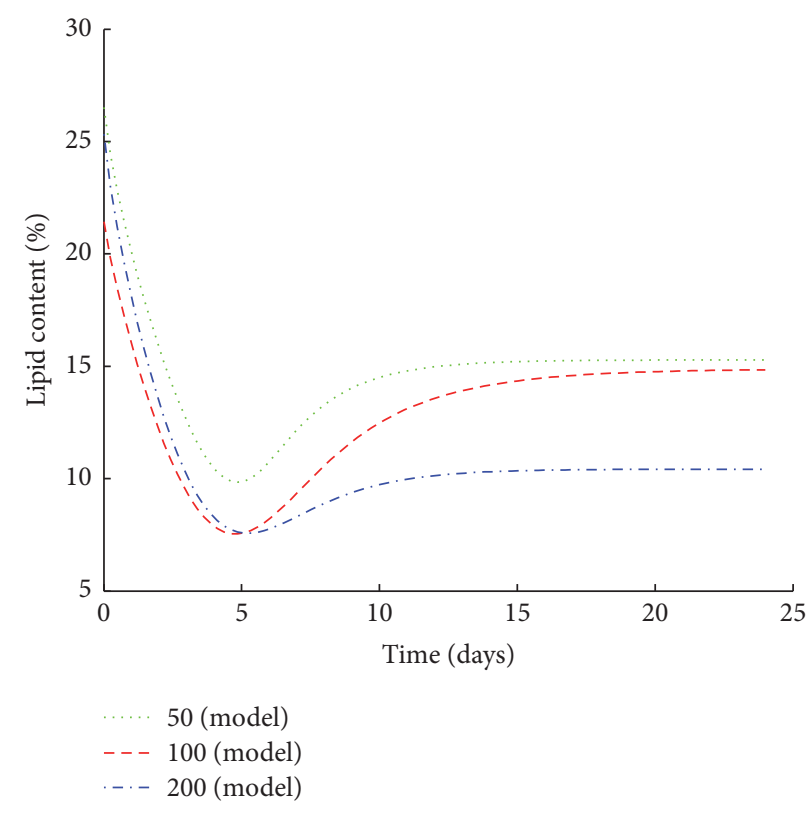

(c)

FiguRE 3: Simulation results of C. sorokiniana versus experimental data for dry weight (a) and predictions of nitrogen consumption (b) and lipid content (c) at different light intensities supplemented.

cultivation condition. Based on (7) and (8), a two-stage cultivation process may be an effective way to reach great lipid productivity, similar to the previous reports [31-34]. The first stage increases biomass by controlling high initial concentration and then improves the lipid content by controlling low initial nitrogen concentration in lipid accumulation stage. This model also can be used for other microalgal species by adjusting parameter values.

3.2. Models Validation in HA-1. The simulation results of (1)(6) for dry weight (Figure $1(\mathrm{a})$ ), $\mathrm{NaNO}_{3}$ concentration (Figure $1(\mathrm{~b})$ ), and lipid content (Figure 1(c)) were in agreement with the experimental data. With the increase of initial nitrogen concentration, the maximum specific growth rate was basically stable. In order to explain the relationship between $h_{0}$ and initial $\mathrm{NaNO}_{3}$ concentration, we fit $h_{0}$ and initial $\mathrm{NaNO}_{3}$ concentration $\left(N_{0}\right)$ to build a linear model: $h_{0}=-1.09 N_{0}-0.6711$. Meanwhile, $\alpha(t)$ is a monotonic function, $\lim _{t \rightarrow \infty} \alpha(t)=1$, when $h_{0}<0, \alpha(t)>1$. Hence, $h_{0}$ can indicate the grow rate of microalgae in difference initial $\mathrm{NaNO}_{3}$ concentrations. The value of $h_{0}$ was negative at different nitrogen concentrations and trended to decrease with an increase of the initial concentration of nitrogen. Figure 1(a) showed the mathematical model fitting of growth with the average of repeated experimental values. For low 


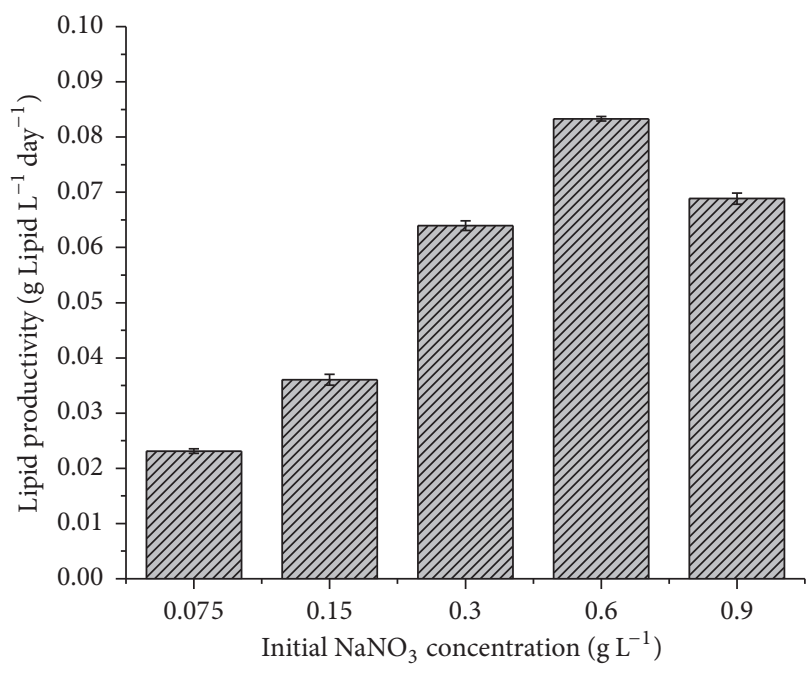

(a)

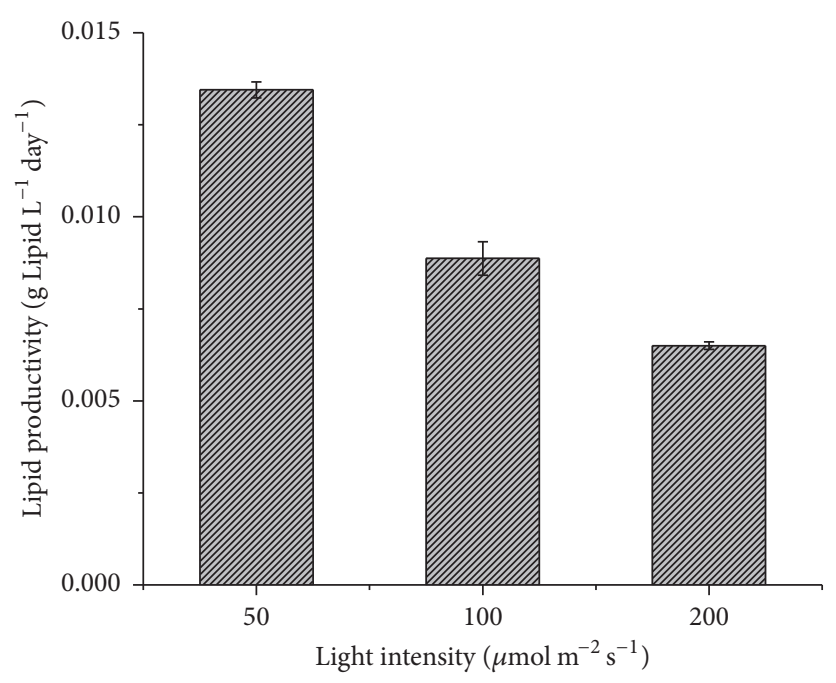

(b)

FIGURE 4: The lipid productivity of Coelastrum sp. HA-1 (a) under various initial $\mathrm{NaNO}_{3}$ concentrations from 0.075 to $0.9 \mathrm{~g} \cdot \mathrm{L}^{-1}$ after 24 days and of C. sorokiniana (b) under various light intensities supplemented from 50 to $200 \mu \mathrm{mol} \cdot \mathrm{m}^{-2} \cdot \mathrm{s}^{-1}$ after 7 days.

nitrogen levels ( 0.075 and $0.15 \mathrm{~g} \cdot \mathrm{L}^{-1} \mathrm{NaNO}_{3}$ ), the short logarithmic phase resulted in low cell density. However, in 0.6 and $0.9 \mathrm{~g} \cdot \mathrm{L}^{-1} \mathrm{NaNO}_{3}$ groups, the logarithmic phase of the cells exceeds 20 days and the maximum biomass was $6.48 \mathrm{~g} \cdot \mathrm{L}^{-1}$ at $0.9 \mathrm{~g} \cdot \mathrm{L}^{-1}$ initial $\mathrm{NaNO}_{3}$ concentration. Figure $1(\mathrm{~b})$ showed that $\mathrm{NaNO}_{3}$ with initial concentrations of $0.075,0.15$, and 0.3 were absolutely depleted at the 4th day and with 0.6 and $0.9 \mathrm{~g} \cdot \mathrm{L}^{-1}$ were depleted at the 8th day. Meanwhile, lipid content was increasing sharply when $\mathrm{NaNO}_{3}$ was depleted and subsequently became stable (Figure $1(\mathrm{c})$ ). The results and (7) imply that biomass and lipid accumulation can be controlled by nitrogen supply in a certain range in terms of other conditions unchanged. However, the varying uncontrollable culture conditions for large scale open outdoor restricted the application. Thus, we further discussed application of light, one of the restricting factors, in our model.

The maximum lipid content was $38 \%$ which was reached in $0.075 \mathrm{~g} \cdot \mathrm{L}^{-1} \mathrm{NaNO}_{3}$ after 24 days. As initial concentration of $\mathrm{NaNO}_{3}$ is increasing, the final lipid content decreased from $38 \%$ to $25 \%$ (Figure $1(\mathrm{c})$ ). These results indicate that nitrogen quota is the key factor for lipid accumulation, especially on the nitrogen limitation condition. The similar results were also reported in previous literatures [24, 35-37].

As illustrated in Table 1, a simple sensitivity analysis for parameters of the model was performed based on two repeats, and all of the parameter values had a range for the model. The sensitivity results show that the model is stable for HA-1 in two repeats.

3.3. Model Application for C. sorokiniana under Photoautotrophic Condition. In order to extend application of the model in other microalgal species under various cultivation conditions, the model was used to predict the growth, $\mathrm{NaNO}_{3}$ consumption, and lipid accumulation of the C. sorokiniana under phototrophic cultivation condition.

Based on these experimental data, the model was used to predict the growth, lipid content, and $\mathrm{NaNO}_{3}$ consumption
(Table 2). The values of the nitrogen-to-protein conversion factor, the carbohydrate content of biomass, and $\Phi$ were estimated according to the final lipid content of $C$. sorokiniana. The parameters $v_{m}$ and $K_{N}$ of Coelastrum sp. HA-1 at $0.9 \mathrm{~g} \cdot \mathrm{L}^{-1}$ initial $\mathrm{NaNO}_{3}$ concentration were used directly; then the final lipid content and the biomass data of $C$. sorokiniana at different light intensity were as target to estimate $\mu_{\max }, h_{0}, k$, $c$, and $\Phi$ using (1), (3), and (6). In addition, the sensitivity analysis was analyzed in Section 3.5 .

The growth of C. sorokiniana was slow (Figure 3(a)) under phototrophic cultivation condition. After 7 days, the maximum dry weight $\left(0.77 \mathrm{~g} \cdot \mathrm{L}^{-1}\right)$ for C. sorokiniana was reached under $50 \mu \mathrm{mol} \cdot \mathrm{m}^{-2} \cdot \mathrm{s}^{-1}$ of light intensity. The data of $\mathrm{NaNO}_{3}$ consumption (Figure 3(b)) of C. sorokiniana were similar to HA-1. According to the predictions, $\mathrm{NaNO}_{3}$ was completely depleted around days 12,12, and 15 at 50, 100, and $200 \mu \mathrm{mol} \cdot \mathrm{m}^{-2} \cdot \mathrm{s}^{-1}$, respectively.

The predictions of lipid content of C. sorokiniana were shown in Figure 3(c) under light intensity of 50, 100, and $200 \mu \mathrm{mol} \cdot \mathrm{m}^{-2} \cdot \mathrm{s}^{-1}$. During logarithmic phase, the lipid content of C. sorokiniana decreased for three types of light conditions. The lipid content of $C$. sorokiniana was to increase when the $\mathrm{NaNO}_{3}$ was depleted at 50,100, and $200 \mu \mathrm{mol} \cdot \mathrm{m}^{-2} \cdot \mathrm{s}^{-1}$; however, the final lipid content for 50 , 100 , and $200 \mu \mathrm{mol} \cdot \mathrm{m}^{-2} \cdot \mathrm{s}^{-1}$ was only $15.28 \%, 14.84 \%$, and $10.42 \%$, respectively (Figure 3(c)), which was lower than initial lipid content. These predictions may imply that, when the growing environment is comfortable for microalgae, the photosynthate is mainly used for growth. Both biomass and lipid content for C. sorokiniana are low under phototrophic condition, which may imply that the C. sorokiniana is not suitable for phototrophic cultivation, or the growth medium may be a bottleneck for growth or lipid accumulation [38].

3.4. Neutral Lipid Productivity of HA-1 and C. sorokiniana. As demonstrated in Figure 4, the maximum neutral lipid productivity of HA-1 was $0.083 \mathrm{~g} \cdot \mathrm{L}^{-1} \cdot \mathrm{day}^{-1}$ for $0.6 \mathrm{~g} \cdot \mathrm{L}^{-1}$ 


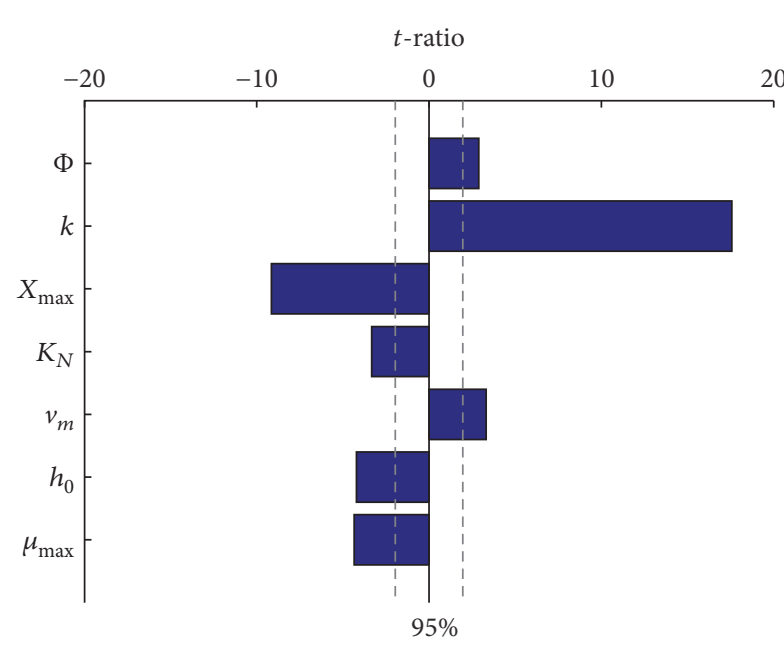

(a)

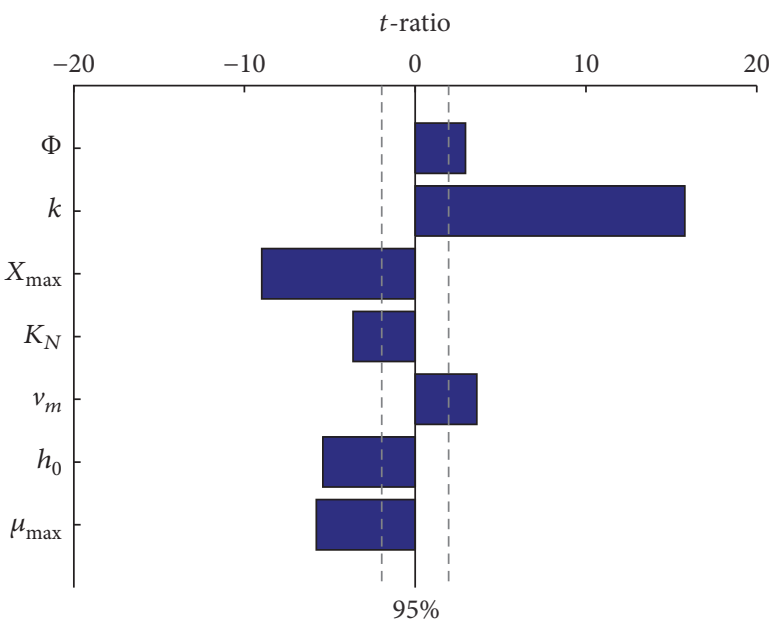

(b)

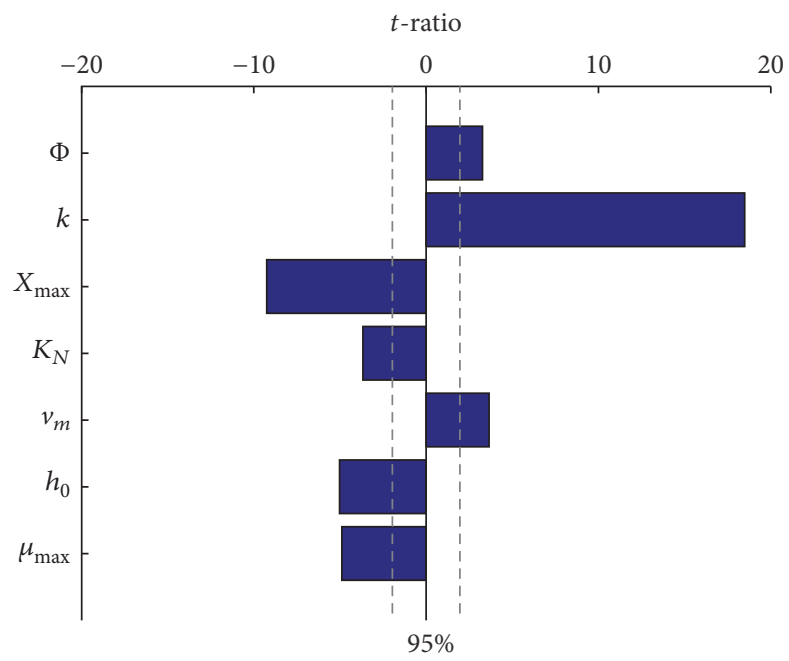

(c)

Figure 5: Sensitivity of model inputs without parameter $c$ (carbohydrate content) for C. sorokiniana under 50 (a), 100 (b), and 200 (c) $\mu \mathrm{mol} \cdot \mathrm{m}^{-2} \cdot \mathrm{s}^{-1}$. Model inputs were altered by $\pm 20 \%$ with lipid content after 24 days compared with baseline lipid content output. Vertical dash lines represent $95 \%$ confidence interval.

initial nitrogen concentration at 24th day. For $0.075,0.15$, 0.3 , and $0.9 \mathrm{~g} \cdot \mathrm{L}^{-1}$ the neutral lipid productivity was 0.023 , $0.036,0.064$, and $0.069 \mathrm{~g} \cdot \mathrm{L}^{-1} \cdot \mathrm{day}^{-1}$, respectively. The lipid productivity of C. sorokiniana was only $0.013,0.0089$, and $0.0065 \mathrm{~g} \cdot \mathrm{L}^{-1} \cdot \mathrm{day}^{-1}$ at 50,100 , and $200 \mu \mathrm{mol} \cdot \mathrm{m}^{-2} \cdot \mathrm{s}^{-1}$, respectively.

3.5. Sensitivity Analysis. As showed in Figure 5, a sensitivity analysis was performed by increasing and decreasing each input by $20 \%$, then estimating $t$-ratios of each input parameter for the variance of lipid content of $C$. sorokiniana using analysis of variance to the model. Sensitivity results for 50 , 100 , and $200 \mu \mathrm{mol} \cdot \mathrm{m}^{-2} \cdot \mathrm{s}^{-1}$ were presented in Figures 5(a), 5(b), and 5(c), respectively.

The $t$-ratio value of parameter $c$ (carbohydrate content) in (6) was not shown in Figure 5, because the relationship between parameter $c$ and lipid content was linear. It was sensitive for the model when the parameter value of carbohydrate content changed. The $t$-ratio values of parameter $c$ were $1.131 \times 10^{16}, 5.796 \times 10^{15}$, and $+\infty$ for 50,100 , and $200 \mu \mathrm{mol} \cdot \mathrm{m}^{-2} \cdot \mathrm{s}^{-1}$, respectively. Hence, the value of parameter $c$ should be firstly determined by mass balance or experiment when the model is applied in other algal species.

For all of light conditions, variables associated with nitrogen-to-protein conversion factor, Baranyi-Roberts parameter, and the maximum algal concentration have a significant effect on lipid accumulation. The model is insensitivity to variance of lipid content in some parameters such as the parameter $\Phi$ under different light conditions.

Those variables with a $t$-ratio greater than the $t$-ratio at 95\% confidence interval have a large effect on the model outputs and thus need to be obtained more accurately than those in this interval when adapting the model to other algal species.

\section{Conclusion}

Lipid content has been modeled by a linear function of nitrogen quota of cell, and the growth of microalgae has 
been simulated by a kinetic model at different initial nitrogen concentrations and light intensities. The model was validated in HA-1 and applied in C. sorokiniana. After sensitivity analysis for the model, carbohydrate content, nitrogen conversion factor, and the maximum algal concentration were significant effect on lipid accumulation. Upregulating initial nitrogen concentrations helped in producing higher biomass, and low nitrogen levels accelerated lipid accumulation. Thus, multiscale regulation of nitrogen was beneficial to get higher lipid productivity in commercial scale.

\section{Competing Interests}

The authors declare that there is no conflict of interests regarding the publication of this paper.

\section{Authors' Contributions}

Zhenhua Yang, Yue Zhao, and Yuyong Hou designed the experiment. Zhenhua Yang and Yue Zhao performed the experiment. Zhiyong Liu analyzed the data with Chenfeng Liu. Zhipeng $\mathrm{Hu}$ and Yuyong Hou wrote the paper. All authors read and agreed on the final paper. Zhenhua Yang and Yue Zhao contributed equally to this work.

\section{Acknowledgments}

The authors thank Fangjian Chen (Tianjin Institute of Industrial Biotechnology, Chinese Academy of Sciences) for analysis of mathematical model. This work was supported partly by the Key Program for International Cooperation Projects of Sino-Canada (no. 155112KYSB20160030), the National Natural Science Foundation of China (Grant no. 31570047), the Hi-Tech Research and Development Program (863) of China (2014AA0221003), and Key Program for International S\&T Cooperation Projects of China (2014DFA61040).

\section{References}

[1] P. Biller and A. B. Ross, "Potential yields and properties of oil from the hydrothermal liquefaction of microalgae with different biochemical content," Bioresource Technology, vol. 102, no. 1, pp. 215-225, 2011.

[2] L. Christenson and R. Sims, "Production and harvesting of microalgae for wastewater treatment, biofuels, and bioproducts," Biotechnology Advances, vol. 29, no. 6, pp. 686-702, 2011.

[3] T. Li, Y. Zheng, L. Yu, and S. Chen, "High productivity cultivation of a heat-resistant microalga Chlorella sorokiniana for biofuel production," Bioresource Technology, vol. 131, pp. 60-67, 2013.

[4] Y. Chisti, "Biodiesel from microalgae beats bioethanol," Trends in Biotechnology, vol. 26, no. 3, pp. 126-131, 2008.

[5] G. Breuer, P. P. Lamers, D. E. Martens, R. B. Draaisma, and R. H. Wijffels, "The impact of nitrogen starvation on the dynamics of triacylglycerol accumulation in nine microalgae strains," Bioresource Technology, vol. 124, pp. 217-226, 2012.

[6] A. Schlesinger, D. Eisenstadt, A. Bar-Gil, H. Carmely, S. Einbinder, and J. Gressel, "Inexpensive non-toxic flocculation of microalgae contradicts theories; overcoming a major hurdle to bulk algal production," Biotechnology Advances, vol. 30, no. 5, pp. 1023-1030, 2012.

[7] L. N. Gerber, J. W. Tester, C. M. Beal, M. E. Huntley, and D. L. Sills, "Target cultivation and financing parameters for sustainable production of fuel and feed from microalgae," Environmental Science and Technology, vol. 50, no. 7, pp. 33333341, 2016.

[8] J. Sheehan, T. Dunahay, J. Benemann, and P. Roessler, A Look Back at the U.S. Department of Energy's Aquatic Species Program Biodiesel from Algae, US Department of Energy, Laboratory NRE, 1998.

[9] P. K. Campbell, T. Beer, and D. Batten, "Life cycle assessment of biodiesel production from microalgae in ponds," Bioresource Technology, vol. 102, no. 1, pp. 50-56, 2011.

[10] H. M. Amaro, A. C. Guedes, and F. X. Malcata, "Advances and perspectives in using microalgae to produce biodiesel," Applied Energy, vol. 88, no. 10, pp. 3402-3410, 2011.

[11] M. Garnier, G. Carrier, H. Rogniaux et al., "Comparative proteomics reveals proteins impacted by nitrogen deprivation in wild-type and high lipid-accumulating mutant strains of Tisochrysis lutea," Journal of Proteomics, vol. 105, pp. 107-120, 2014.

[12] N.-A. T. Tran, M. P. Padula, C. R. Evenhuis, A. S. Commault, P. J. Ralph, and B. Tamburic, "Proteomic and biophysical analyses reveal a metabolic shift in nitrogen deprived Nannochloropsis oculata," Algal Research, vol. 19, pp. 1-11, 2016.

[13] Y. Li, D. Han, M. Sommerfeld, and Q. Hu, "Photosynthetic carbon partitioning and lipid production in the oleaginous microalga Pseudochlorococcum sp. (Chlorophyceae) under nitrogen-limited conditions," Bioresource Technology, vol. 102, no. 1, pp. 123-129, 2011.

[14] M.-E. Hong, Y. Y. Choi, and S. J. Sim, "Effect of red cyst cell inoculation and iron (II) supplementation on autotrophic astaxanthin production by Haematococcus pluvialis under outdoor summer conditions," Journal of Biotechnology, vol. 218, pp. 2533, 2016.

[15] V. H. Work, R. Radakovits, R. E. Jinkerson et al., "Increased lipid accumulation in the Chlamydomonas reinhardtii sta710 starchless isoamylase mutant and increased carbohydrate synthesis in complemented strains," Eukaryotic Cell, vol. 9, no. 8, pp. 1251-1261, 2010.

[16] B. Wang, Z. Zhang, Q. Hu et al., "Changing lipid profiles across life cycle stages of the green alga Haematococcus pluvialis," PLoS ONE, vol. 9, no. 9, Article ID e106679, 2014.

[17] Y. Suen, J. S. Hubbard, G. Holzer, and T. G. Tornabene, “Total lipid production of the green alga Nannochloropsis sp. QII under different nitrogen regimes," Journal of Phycology, vol. 23, supplement 2, pp. 289-296, 1987.

[18] T. Legović and A. Cruzado, "A model of phytoplankton growth on multiple nutrients based on the Michaelis-Menten-Monod uptake, Droop's growth and Liebig's law," Ecological Modelling, vol. 99, no. 1, pp. 19-31, 1997.

[19] R. J. Geider, H. L. MacIntyre, and T. M. Kana, "A dynamic regulatory model of phytoplanktonic acclimation to light, nutrients, and temperature," Limnology and Oceanography, vol. 43, no. 4, pp. 679-694, 1998.

[20] J. Quinn, L. de Winter, and T. Bradley, "Microalgae bulk growth model with application to industrial scale systems," Bioresource Technology, vol. 102, no. 8, pp. 5083-5092, 2011. 
[21] J. Baranyi, T. A. Roberts, and P. McClure, "A non-autonomous differential equation to model bacterial growth," Food Microbiology, vol. 10, no. 1, pp. 43-59, 1993.

[22] J. Baranyi and T. A. Roberts, "A dynamic approach to predicting bacterial growth in food," International Journal of Food Microbiology, vol. 23, no. 3-4, pp. 277-294, 1994.

[23] R. Tevatia, Y. Demirel, and P. Blum, "Kinetic modeling of photoautotropic growth and neutral lipid accumulation in terms of ammonium concentration in Chlamydomonas reinhardtii," Bioresource Technology, vol. 119, pp. 419-424, 2012.

[24] A. Packer, Y. Li, T. Andersen, Q. Hu, Y. Kuang, and M. Sommerfeld, "Growth and neutral lipid synthesis in green microalgae: a mathematical model," Bioresource Technology, vol. 102, no. 1, pp. 111-117, 2011.

[25] A. Richmond, Handbook of Microalgal Culture: Biotechnology and Applied Phycology, Wiley-Blackwell, Oxford, UK, 2004.

[26] R. R. Guillard and J. H. Ryther, "Studies of marine planktonic diatoms. I. Cyclotella nana Hustedt, and Detonula confervacea (cleve) Gran," Canadian Journal of Microbiology, vol. 8, pp. 229239, 1962.

[27] A. Kuhl and H. Lorenzen, "Chapter 10 Hmdling and Culturing of Chlorella," Methods in Cell Biology, vol. 1, pp. 159-187, 1964.

[28] Y. Hou, Z. Liu, Y. Zhao, S. Chen, Y. Zheng, and F. Chen, "CAH1 and CAH2 as key enzymes required for high bicarbonate tolerance of a novel microalga Dunaliella salina HTBS," Enzyme and Microbial Technology, vol. 87-88, pp. 17-23, 2016.

[29] C. Yuan, J. Liu, Y. Fan, X. Ren, G. Hu, and F. Li, "Mychonastes afer HSO-3-1 as a potential new source of biodiesel," Biotechnology for Biofuels, vol. 4, no. 1, article 47, 2011.

[30] W. Xiong, C. Gao, D. Yan, C. Wu, and Q. Wu, "Double $\mathrm{CO}_{2}$ fixation in photosynthesis-fermentation model enhances algal lipid synthesis for biodiesel production," Bioresource Technology, vol. 101, no. 7, pp. 2287-2293, 2010.

[31] G. Mujtaba, W. Choi, C.-G. Lee, and K. Lee, "Lipid production by Chlorella vulgaris after a shift from nutrient-rich to nitrogen starvation conditions," Bioresource Technology, vol. 123, pp. 279283, 2012.

[32] P. D. Álvarez-Díaz, J. Ruiz, Z. Arbib, J. Barragán, C. GarridoPérez, and J. A. Perales, "Lipid production of microalga ankistrodesmus falcatus increased by nutrient and light starvation in a two-stage cultivation process," Applied Biochemistry and Biotechnology, vol. 174, no. 4, pp. 1471-1483, 2014.

[33] H. Abedini Najafabadi, M. Malekzadeh, F. Jalilian, M. Vossoughi, and G. Pazuki, "Effect of various carbon sources on biomass and lipid production of Chlorella vulgaris during nutrient sufficient and nitrogen starvation conditions," Bioresource Technology, vol. 180, pp. 311-317, 2015.

[34] M. M. R. Shah, Y. Liang, J. J. Cheng, and M. Daroch, "Astaxanthin-producing green microalga Haematococcus pluvialis: from single cell to high value commercial products," Frontiers in Plant Science, vol. 7, article 531, 25 pages, 2016.

[35] N. S. Shifrin and S. W. Chisholm, "Phytoplankton lipids: interspecific differences and effects of nitrate, silicate and light-dark cycles," Journal of Phycology, vol. 17, no. 4, pp. 374-384, 1981.

[36] M. Piorreck, K.-H. Baasch, and P. Pohl, "Biomass production, total protein, chlorophylls, lipids and fatty acids of freshwater green and blue-green algae under different nitrogen regimes," Phytochemistry, vol. 23, no. 2, pp. 207-216, 1984.

[37] A. M. Illman, A. H. Scragg, and S. W. Shales, "Increase in Chlorella strains calorific values when grown in low nitrogen medium," Enzyme and Microbial Technology, vol. 27, no. 8, pp. 631-635, 2000.
[38] B. Cheirsilp and S. Torpee, "Enhanced growth and lipid production of microalgae under mixotrophic culture condition: effect of light intensity, glucose concentration and fed-batch cultivation," Bioresource Technology, vol. 110, pp. 510-516, 2012. 

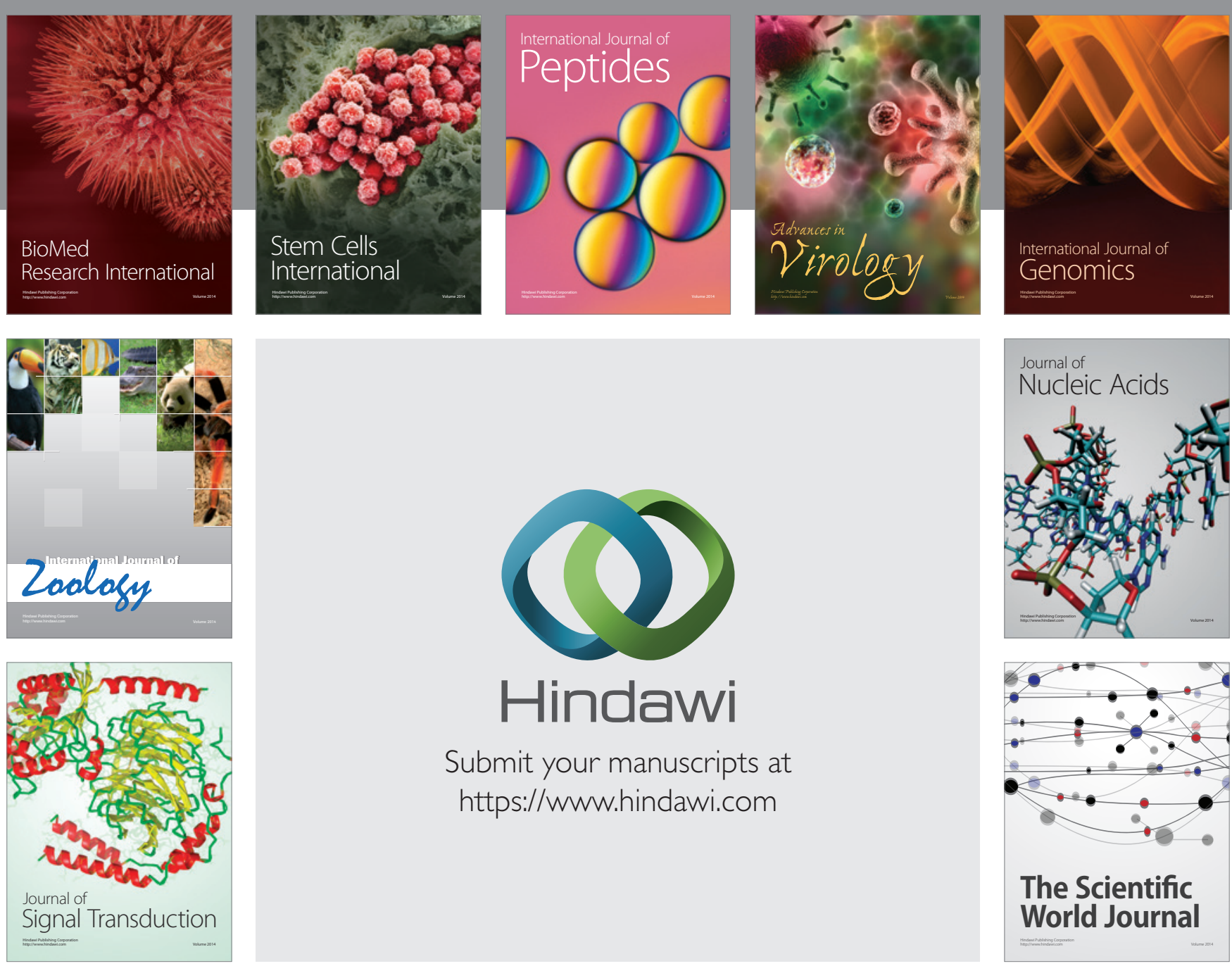

Submit your manuscripts at

https://www.hindawi.com
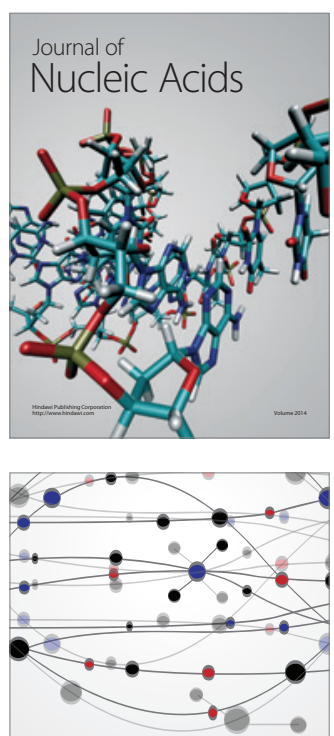

The Scientific World Journal
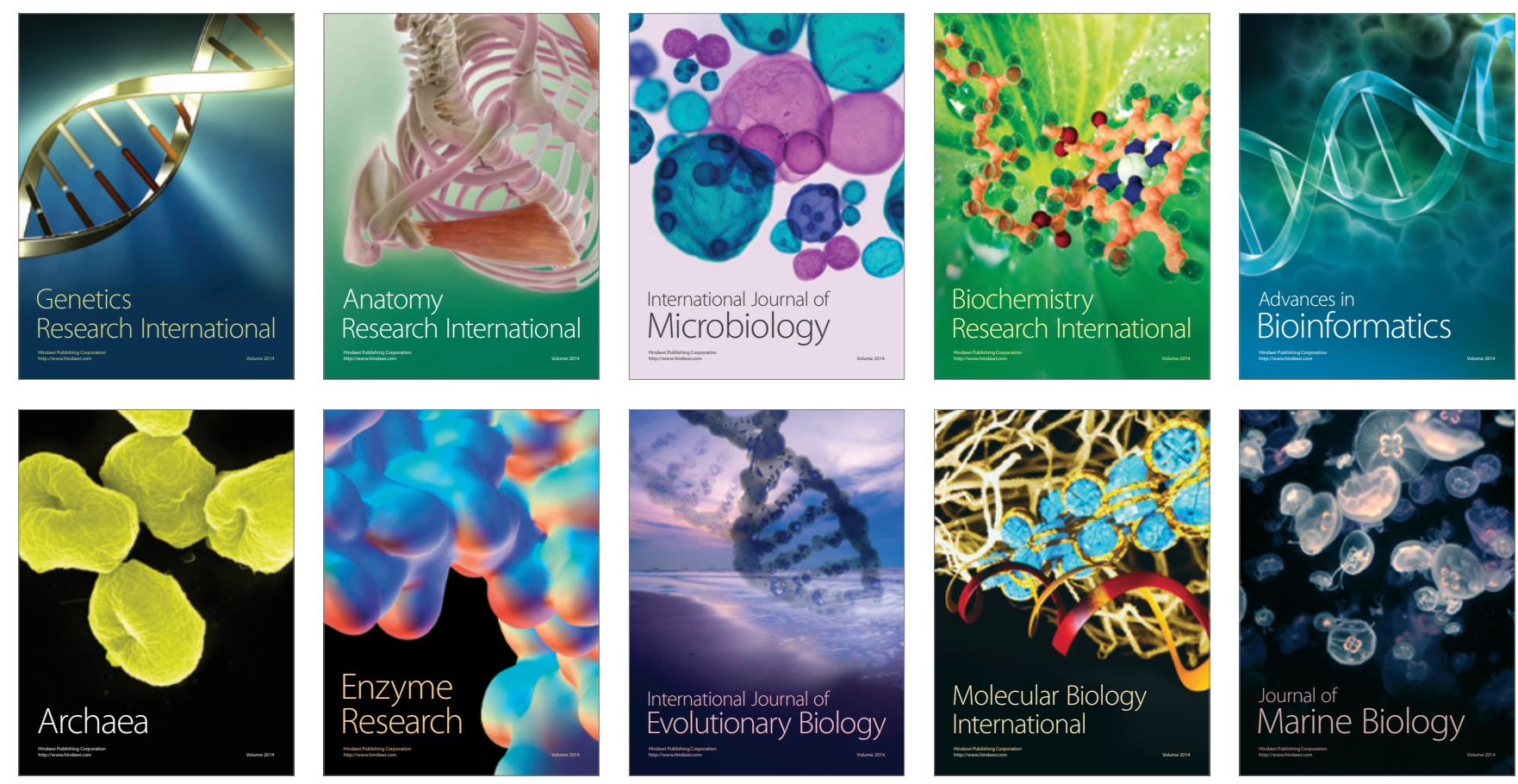